\title{
Pembuatan dan Pelatihan Website Administrasi Desa Bukit Lingkar Kecamatan Batang Cenaku Kabupaten Indragiri Hulu
}

\section{Creation and Training of Village Administration Website of Bukit Lingkar Village Batang Cenaku District Indragiri Hulu Regency}

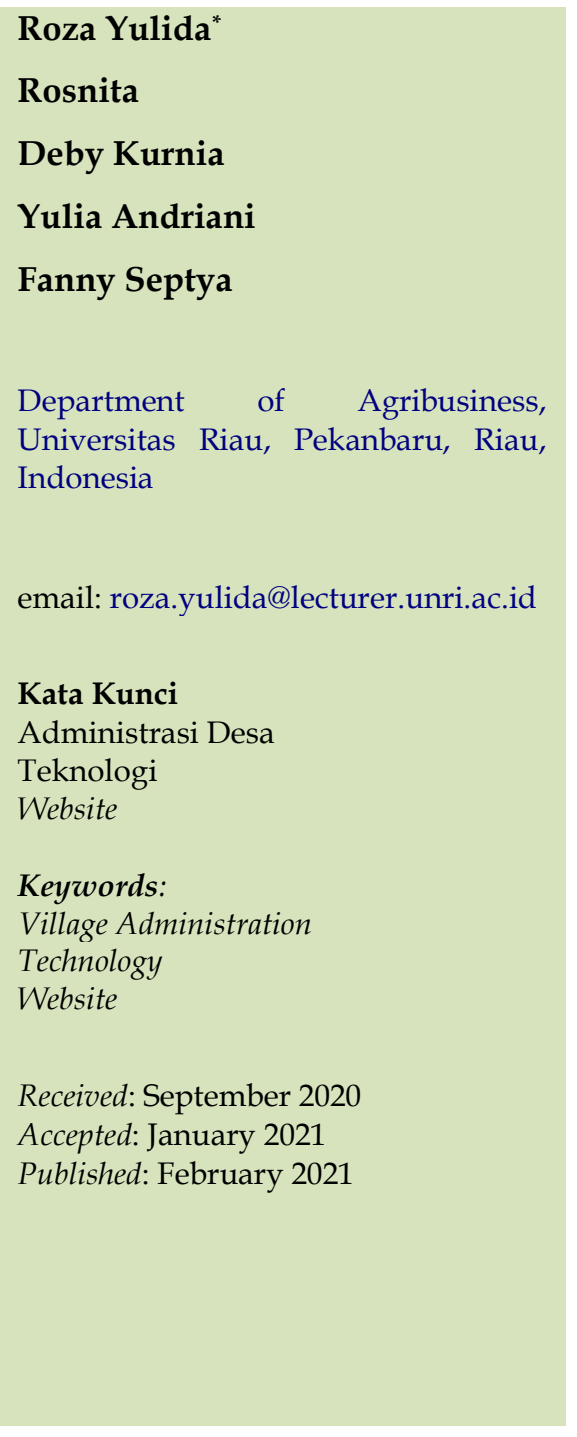

\begin{abstract}
Abstrak
Website merupakan keseluruhan halaman web yang mengandung informasi yang sangat besar yang terdapat dalam sebuah domain. Informasi yang ada di dalam web dipresentasikan ke dalam sebuah halaman web yang terbentuk dari sekumpulan teks, grafik, gambar, suara, dan video. Website akan memudahkan suatu intansi, organisasi dan lain sebagainya dalam memuat informasi yang dapat diakses oleh masyarakat banyak. Perkembangan teknologi informasi menuntut Kabupaten Indragiri Hulu umumnya Desa Bukit Lingkar bisa mengakses dan mengetahui informasi yang diharapkan tentang seputar Desa. Tujuan kegiatan ini adalah merancang sebuah Website Administrasi Desa dan memberikan pelatihan masyarakat tentang tata cara pengggunaan website tersebut. Terdapat beberapa metode penerapan kegiatan seperti pelatihan pembuatan website kepada Mahasiswa Kukerta, pelatihan kepada admin pemerintah desa dalam mengelola website hingga pada launching website. Kegiatan ini dimulai dengan rentan waktu Juli hingga Agustus 2020.
\end{abstract}

\begin{abstract}
A website is a whole web page that contains enormous information contained in a domain. Information on the web is presented on a web page which is formed from a collection of text, graphics, images, sound, and video. The purpose of making a website is to facilitate an agency, organization, and so on in containing information that can be accessed by the public at large. With the development of information technology, Indragiri Hulu District, in general, Bukit Lingkar Village, can access and find out the expected information about the village. Therefore we tried to design a Village Administration Website which later on the website will contain information about the Village and Village information in Bukit Lingkar Village and provide community training on how to use the website. In the process of creating and training this website, there are several activities carried out such as training on creating websites for Kukerta students, training for village government administrators in managing the website to launching the website. This activity starts with a vulnerable time from July to August 2020.
\end{abstract}

() 2021 Roza Yulida, Rosnita, Deby Kurnia, Yulia Andriani, Fanny Septya. Published by Institute for Research and Community Services Universitas Muhammadiyah Palangkaraya. This is Open Access article under the CC-BYSA License (http://creativecommons.org/licenses/by-sa/4.0/). https://doi.org/10.33084/pengabdianmu.v6i2.1677

\section{PENDAHULUAN}

Kemajuan teknologi informasi mengalami perkembangan yang sangat pesat, sekarang ini dengan kebutuhan akan adanya sistem informasi berbasis komputer pun semakin meningkat hampir semua bidang dan pekerjaan untuk menyampaikan informasi menggunakan teknologi komputer. Perkembangan teknologi dan informasi menjadi hal yang sangat penting dalam dunia, karena masa informasi adalah masa yang canggih dan kompleks, kemudian penuh dinamika dan perubahan terus-menerus. Kondisi seperti ini menuntut 
berkembangnya teknologi informasi yang canggih dan menghasilkan informasi yang cepat, efisien, dan efektif. Perkembangan teknologi informasi dan tekonologi komputer dalam bidang ilmu pengetahuan, pendidikan, bisnis, administrasi perkantoran, komunikasi, pemerintahan dan kegiatan lain, dalam kehidupan sehari-hari memegang peranan yang cukup besar di negara ini dalam proses pembangunan secara menyeluruh (Ngafifi, 2014).

Website saat ini muncul karena adanya kebutuhan pasar serta masyarakat yang semakin tinggi dibidang teknologi. Website saat ini tidak hanya menyediakan jasa atau sebagai company profile terhadap suatu perusahaan, tetapi juga menjadi tempat jual dan beli, hiburan, forum, dan berbagai kreativitas lainnya yang dapat menunjang dan memiliki daya tarik lebih untuk menarik pasar dan konsumennya agar memakai jasanya atau sekedar melihat (Yuliana, 2000).

Administrasi merupakan pencatatan data dan informasi dalam mendukung penyelenggaraan Pemerintahan Desa, maka perlu dilakukan langkah penyempurnaan terhadap pelaksanaan administrasi. yang mengatur materi mengenai Asas Pengaturan, Kedudukan dan Jenis Desa, Penataan Desa, Keuangan Desa dan Aset Desa, Pembangunan Desa dan Pembangunan Kawasan Perdesaan, Badan Usaha Milik Desa, Kerjasama Desa, serta Pembinaan dan Pengawasan. Berdasarkan pada awalnya perumusan secara formal desa dalam UndangUndang Nomor 5 Tahun 1979 tentang Pemerintahan Desa, dikatakan bahwa desa adalah suatu wilayah yang ditempati oleh sejumlah penduduk sebagai kesatuan masyarakat termasuk didalamnya kesatuan masyarakat hukum yang mempunyai organisasi pemerintahan terendah langsung dibawah Camat dan berhak menyelenggarakan rumah tangganya sendiri dalam ikatan Negara Kesatuan Republik Indonesia. Dengan diundangkannya Undang-Undang Nomor 32 Tahun
2004 tentang Pemerintahan Daerah, telah membawa perubahan yang mendasar dalam sistem dan struktur Pemerintahan Daerah serta membawa dampak yang sangat luas bagi penyelenggaraan pemerintahan, perencanaan pembangunan, pengelolaan keuangan dan sistem penganggaran dalam menunjang penyelenggaraan pemerintahan di Daerah, khususnya pada tingkat Pemerintahan Desa. Untuk meningkatkan manajemen Pemerintahan Desa perlu dilakukan penataan administrasi agar lebih efektif dan efisien, dimana penataan. Website juga membantu meningkatkan kualitas pelaporan kinerja desa (Arianto, 2018).

Desa atau nama lainnya, sebagai sebuah entitas budaya, ekonomi dan politik yang telah ada sebelum produkproduk hukum masa kolonial dan sesudahnya, diberlakukan, telah memiliki asas-asas pemerintahan sendiri yang asli, sesuai dengan karakteristik sosial dan ekonomi, serta kebutuhan dari rakyatnya. Konsep desa tidak hanya sebatas unit geografis dengan jumlah penduduk tertentu, melainkan sebagai sebuah unit teritorial yang dihuni oleh sekumpulan orang dengan kelengkapan budaya termasuk sistem politik dan ekonomi yang otonom. Pengelolaan desa didasarkan pada pengelolaan potensi yang terangkum dalam sistem manajemen dan didukung oleh sistem informasi. Website sebagai manifestasi kemajuan teknologi mendukung kebutuhan akan hal tersebut (Setiawan, 2018; Muntoha et al., 2015). Website sebagai bagian dari kinerja internet memberi dampak baik positif maupun negatif bagi budaya masyarakat, serta meningkatkan presepsi dan pengetahuan masyarakat melalui transparansi dan aksesibiltas informasi (Yusuf, 2016) sehingga informasi tentang desa yang merupakan unsur implisit dari pembangunan terencana dapat sampai ke masyarakat (Ahmad, 2012). Website desa akan meningkatkan arus informasi, pelayanan desa, dan dapat sebagai sarana 
promosi desa (Sutrisno \& Trisnawarman, 2019) serta meningkatkan jumlah desa online (Zulfa et al., 2017).

Pelayanan aparatur desa yang belum efisien dan efektif, menyebabkan banyak keluhan dan pengaduan masyarakat dalam pelayanan dari aparatur desa (Noviyanto et al., 2014). Masih rendahnya kemampuan aparat desa dalam memanfaatkan teknologi informasi dalam melayani masyarakat sehingga belum baiknya pelayanan kepada masyarakat (Rianto et al., 2019). Oleh karena itu diperlukan pelatihan dan pendampingan bagi aparat desa dalam meningkatkan kemampuan dan profesionalisme aparat pemerintah dalam menggunakan teknologi informasi (Kuswandi et al., 2018).

Desa Bukit Lingkar Kecamatan Batang Cenaku Kabupaten Indragiri Hulu, memiliki keunggulan dibandingkan desa lainnya, dengan potensi perkebunan kelapa sawit yang besar dalam mendukung perekonomian masyarakatnya. Pembangunan desa akan lebih maksimal jika potensi sumber day aini selaras dengan kemudahan administrasi yang dibutuhkan masyarakat. Namun kondisi Desa Bukit Lingkar Kecamatan Batang Cenaku Kabupaten Indragiri Hulu belum didukung oleh pelayanan yang maksimal dari pegawai desa dalam melayani kebutuhan administrasi masyarakat Permasalahan-permasalahan tersebut, seperti:

1. Masih kurangnya pengetahuan dan keterampilan pegawai desa dalam memanfaatkan teknologi informasi dan komunikasi dalam melayani administrasi masyarakat desa.

2. Belum terdatanya secara baik administrasi desa karena belum adanya perangkat teknologi yang mendukung untuk pengelolaan administrasi desa

3. Pelayanan masyarakat belum seragam, cenderung lama dan bahkan kadang-kadang masyarakat harus bolak balik mengurus karena adanya bahan yang dianggap kurang karena belum adanya format yang seragam dan teknologi komunikasi yang mendukung dalam melayani keperluan adaministrasi masyarakat, seperti mengurus KTP, KK, dan surat keterangan lainnya.

Oleh karena itu, Tim Kukerta Terintegrasi Abdimas Universitas Riau membuatkan sistem yang akan memperkenalkan instansi dengan cara membuatkan website administrasi desa, website tersebut berguna untuk semua masyarakat agar mendapatkan informasiinformasi, semua kegiatan dan memperkenalkan semua staff dan pengurus kantor desa tersebut. Tim pengabdian masyarakat dan mahasiswa kukerta terintegrasi melakukan kegiatan pengabdian masyarakat yang bertujuan untuk membuat sebuah situs website kantor desa yang dinamis. Website tersebut bermanfaat sebagai sarana informasi dan promosi bagi desa (Muntoha et al., 2015).

\section{METODOLOGI}

Kegiatan ini diawali dengan melakukan diskusi terkait kebutuhan program pembuatan website Desa bagi Desa Bukit Lingkar. Tahapan berikutnya yakni pelatihan website kepada mahasiswa kukerta terintegrasi yang dilaksanakan di awal masa kukerta. Prose pembuatan website dimulai dengan pengumpulan data-data yang dibutuhkan, menginput data ke dalam website, peluncuran website serta pelatihan website kepada admin yang telah di tunjuk dalam mengelola website dan pelatihan penggunaan website kepada kelompok tani. Metode penerapan pembuatan website tersebut dijelaskan dalam tahapan kegiatan dalam tabel berikut:

\begin{tabular}{cclll} 
Tabel I. & \multicolumn{2}{c}{ Metode pelaksanaan } & & \\
\hline No & $\begin{array}{c}\text { Waktu } \\
\text { Pelaksanaan }\end{array}$ & \multicolumn{1}{c}{ Kegiatan } & Stakeholder & Durasi \\
\hline 1. & 10 Juli 2020 & $\begin{array}{l}\text { Diskusi dengan } \\
\text { pihak desa } \\
\text { terkait } \\
\text { kebutuhan } \\
\text { website }\end{array}$ & $\begin{array}{l}\text { Perangkat } \\
\text { Desa, }\end{array}$ & 1 jam \\
& & & \\
& & & \\
\hline
\end{tabular}




\begin{tabular}{|c|c|c|c|c|}
\hline 2. & 13 Mei 2020 & Pelatihan & DPL, & 40 \\
\hline & & $\begin{array}{l}\text { Website kepada } \\
\text { mahasiswa }\end{array}$ & Mahasiswa & menit \\
\hline 3. & 22 Juli 2020 & $\begin{array}{l}\text { Pengumpulan } \\
\text { Data }\end{array}$ & $\begin{array}{l}\text { Perangkat } \\
\text { Desa, } \\
\text { Mahasiswa }\end{array}$ & 1 jam \\
\hline 4. & 30 Juli 2020 & $\begin{array}{l}\text { Penginputan } \\
\text { Data }\end{array}$ & Mahasiswa & 10 hari \\
\hline 5. & $\begin{array}{l}27 \text { Agustus } \\
2020\end{array}$ & $\begin{array}{l}\text { Penyempurnaan } \\
\text { Website }\end{array}$ & Mahasiswa & 4 hari \\
\hline 6. & $\begin{array}{l}29 \text { Agustus } \\
2020\end{array}$ & $\begin{array}{l}\text { Lokakarya dan } \\
\text { Peluncuran } \\
\text { Website }\end{array}$ & $\begin{array}{l}\text { Perangkat } \\
\text { Desa, DPL, } \\
\text { Mahasiswa }\end{array}$ & 3 jam \\
\hline 7. & $\begin{array}{l}31 \text { Agustus } \\
2020\end{array}$ & $\begin{array}{l}\text { Pelatihan } \\
\text { pengelolaan } \\
\text { website oleh } \\
\text { admin }\end{array}$ & $\begin{array}{l}\text { Admin(dari } \\
\text { perangkat } \\
\text { desa) dan } \\
\text { mahasiswa }\end{array}$ & 3 jam \\
\hline
\end{tabular}

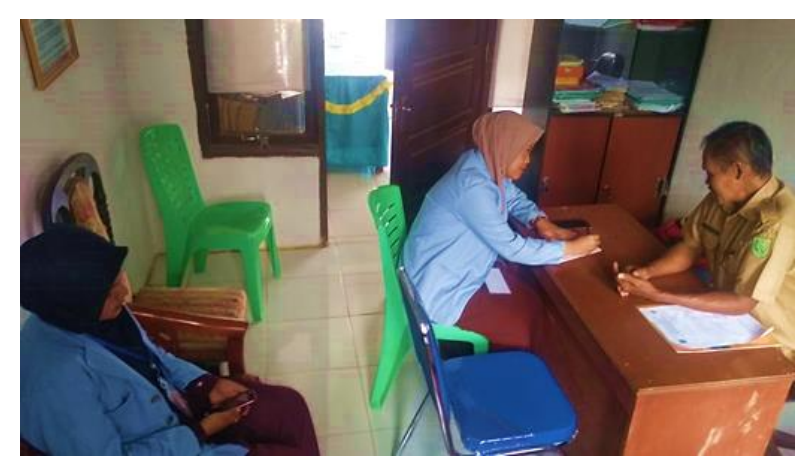

Gambar 1. Pengambilan Data Website

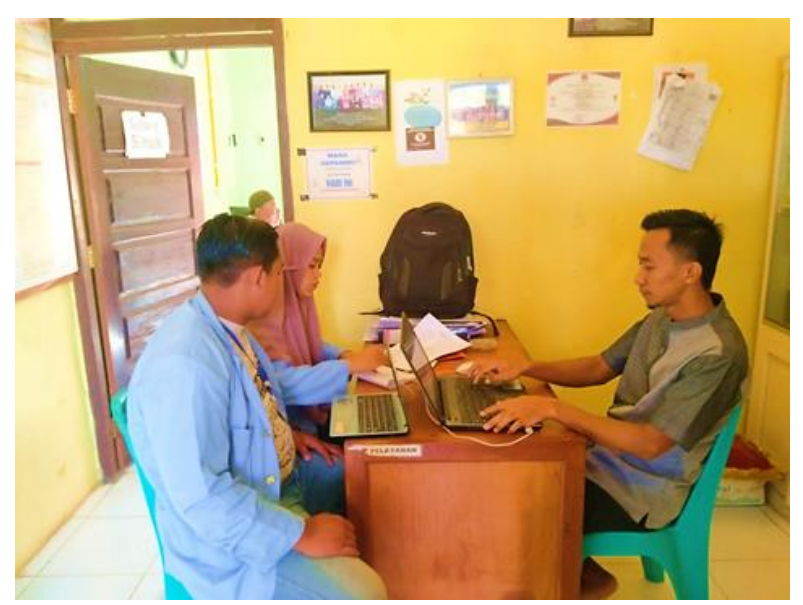

Gambar 2. Penyerahan Website pada Admin

\section{HASIL DAN PEMBAHASAN}

Setelah melakukan survei lokasi kegiatan dilanjutkan dengan pengenalan dan pelatihan pembuatan website kepada mahasiswa kukerta yang dilaksanakan selama 2 (dua) kali pertemuan dan dilatih oleh tim Dosen Pembimbingg Lapangan (DPL). Selanjutnya kegiatan dilanjutkan dengan pembuatan website yang dilakukan oleh mahasiswa kukerta setelah memahami dan mengetahui terkait website itu sendiri.
Kemudian kegiatan dilanjutkan dengan pengumpulan data-data yang dibutuhkan untuk website, proses pengumpulan data ini dilakukan di Kantor Desa langsung. Pengimputan data kedalam website, setelah melakukan pengumpulan data-data yang dibutuhkan selanjutnya data tersebut diinput kedalam website.

Setelah pengimputan berbagai data-data maka website siap untuk peluncuran dan pelatihan kepada admin untuk mengelola website tersebut. Dalam memilih admin Tim Kukerta dan DPL berkoordinasi dengan Petugas Penyuluh Lapangan (PPL) untuk menentukan siapa yang akan menjadi admin. Selain melakukan pelatihan kepada admin, juga dilakukan pelatihan pengaplikasian website dan masyarakat terkait tata cara membuka webiste untuk membaca informasi-informasi yang disajikan.Tindak lanjut dari program pembuatan website ini adalah masyarakat mampu membaca informasi yang ada di website tersebut sehingga membantu meningkatkan tentang informasi terbaru seputar Desa dan pentingnya teknologi dalam menunjang penyebaran informasi tersebut dan admin telah dilatih dan mampu untuk mengelola website.

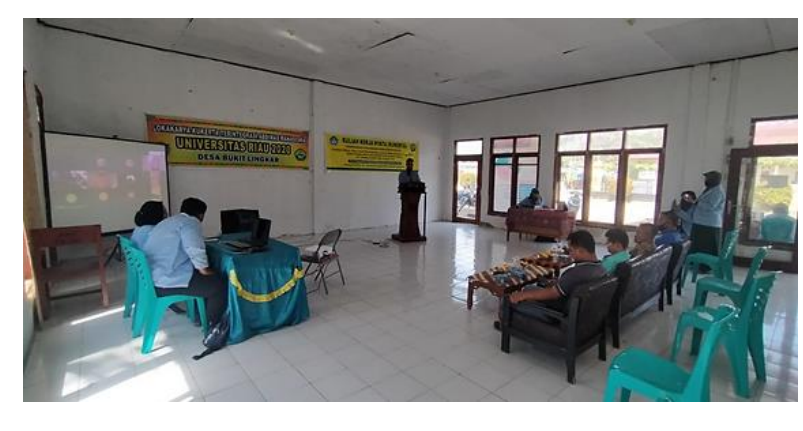

Gambar 3. Launching Website Desa

Website Desa yang telah dikelola memiliki beberapa fitur pendukung yakni beranda, profil desa, struktur lembaga, blog, kontak, galeri dan LPPM UNRI sebagai mitra desa. Pada beranda tercantum informasi desa terbaru serta informasi administrasi yang dibutuhkan masyarakat. Pada fitur blog dimuat artikel oleh admin dan mahasiswa yang bertujuan meningkatkan 
prespektif dan pengetahuan masyarakat. Beberapa tampilan fitur Website Desa adalah sebagai berikut:

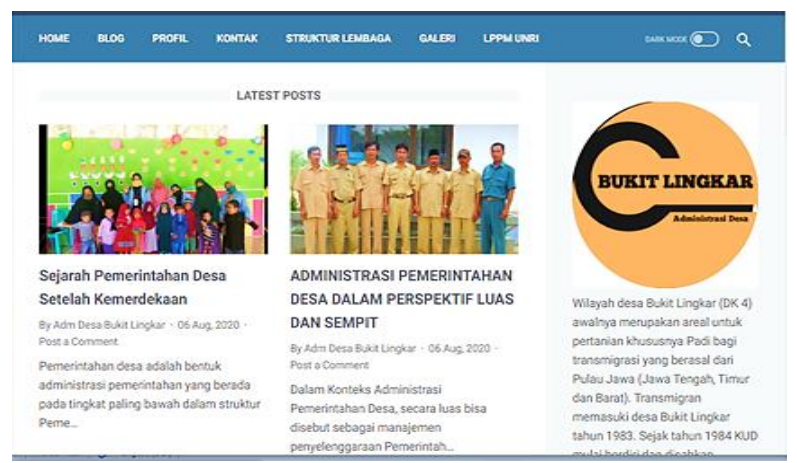

Gambar 4. Tampilan Depan Website

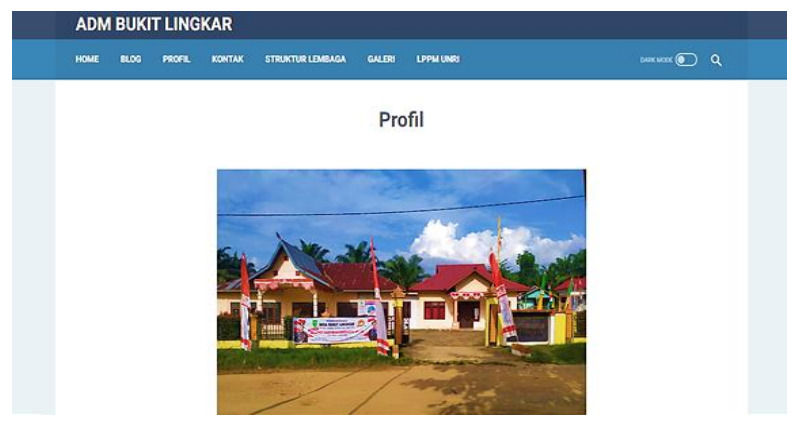

Gambar 5. Tampilan Fitur Profil Desa

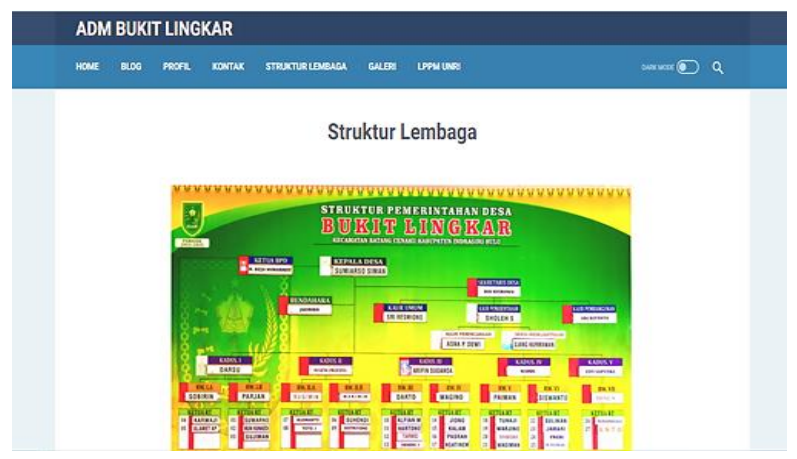

Gambar 6. Tampilan Fitur Struktur Lembaga Desa

\section{KESIMPULAN}

Pelaksanaan pembuatan website desa berjalan dengan lancar dan sesuai rencana. Website Desa berjalan secara offline dan online dan mulai diakses masyarakat khususnya informasi tentang persyaratan administrasi. Admin didukung oleh pengelola desa diharapkan terus memperbarui informasi sesuai kebutuhan masyarakat. Pengabdian masyarakat oleh Universitas Riau sebagai mitra perlu melakukan monitoring dan pelatihan berkala bagi admin agar website tetap terkelola dan terperbaharui sehingga berkembang menjadi media informasi dan promosi.

\section{UCAPAN TERIMA KASIH}

Ucapan terimakasih kepada Lembaga Penelitian dan Pengabdian kepada Masyarakat Universitas Riau, Perangkat Desa Kota Lingkar, Mentor Pelatihan Website, Mahasiswa Kukerta Terintegrasi, Admin serta masyarakat desa yang telah mendukung dan membantu kelancaran pembuatan website desa.

\section{REFERENSI}

Ahmad, A. 2012. Perkembangan Teknologi Komunikasi dan Kesenjangan Informasi: Akar Informasi dan Berbagai Standarnya. Jurnal Dakwah Tabligh.

13(1):137-149. https://doi.org/10.24252/jdt.v13i1.300

Arianto, I.D. 2018. Pemanfaatan Teknologi Komunikasi Dan Informasi Di Desa Kesamben Kecamatan Kesamben Jombang. Dinamika Governance: Jurnal Ilmu Administrasi Negara. 8(1):62-68. https://doi.org/10.33005/jdg.v8i1.1216

Kuswandi, A., Kurniasih, D., Karniawati, N. 2018. Pelatihan E-Government Bagi Aparat Pemerintah Desa Di Kecamatan Ciampel Kabupaten Karawang. Jurnal Abdimas Mandiri. 2(1):1-10. https://doi.org/10.36982/jam.v2i1.433

Muntoha, Jamroni, \& Tantria, H. 2015. PemanfaatanSitus Web sebagai Sarana Promosi Desa Songbanyu, Kecamatan Giri Subo, Gunung Kidul, Daerah Istimewa Yogyakarta. AJIE (Asian Journal of Innovation and Entrepreneurship). 4(3):172-176.

Ngafifi, M. 2014. Kemajuan Teknologi Dan Pola Hidup Manusia Dalam Perspektif Sosial Budaya. Jurnal Pembangunan Pendidikan: Fondasi dan Aplikasi.

2(1):33-47. https://doi.org/10.21831/jppfa.v2i1.2616

Noviyanto, F., Setiyadi, T., Wahyuningsih, I. 2014. Implementasi SIKADES (Sistem Informasi Kependuduan Desa) untuk Kemudahan 
Layanan Administrasi Desa Berbasis Web Mobile. Jurnal Informatika. 8(1):858-869. http://dx.doi.org/10.26555/jifo.v8i1.a2084

Rianto, R., Mubarak, H., Aradea, A. 2019. Pelatihan Penerapan Sistem Layanan Administrasi Penduduk Desa Berbasis Teknologi Informasi. Jurnal Pengabdian Siliwangi. 5(1):16-18.

Setiawan, D. 2018. Dampak Perkembangan Teknologi Informasi dan Komunikasi Terhadap Budaya. Jurnal Simbolika: Research and Learning in Comunication Study. 4(1):62-72. https://doi.org/10.31289/simbollika.v4i1.147 4

Sutrisno, T., Trisnawarman, D. 2019. Pembuatan Dan Implementasi Website Desa Pandowoharjo. Jurnal Bakti Masyarakat Indonesia. 1(2):211-220. https://doi.org/10.24912/jbmi.v1i2.2905

Yuliana, O. 2000. Penggunaan Teknologi Internet Dalam Bisnis. Jurnal Akuntansi dan Keuangan. 2(1):3652.

https://doi.org/10.9744/jak.2.1.pp.\%2036-52

Yusuf, I. 2016. Analisis Penggunaan Teknologi Informasi (Internet) Terhadap Masyarakat Di Kecamatan Sigi Biromaru Kabupaten Sigi. Katalogis. 4(9):125-136.

Zulfa, M.I., Fadli, A., Widhiatmoko, H. 2017. Pendampingan Program Pelatihan Pengelolaan. In Prosiding Seminar Nasional Pengembangan Sumber Daya Perdesaan dan Kearifan Lokal Berkelanjutan VII, 17-18 November 2017. Purwokerto, Universitas Jenderal Soedirman. 